\title{
J(৫)
}

Received: 01.11.2018

Accepted: 05.01.2019

Published: 10.01 .2019

JOTS, 3/1, 2019: 83-90

\section{Eski Türk Sivil Belgelerinde Resmî ve Edebî Üslubun Senkretizmi Meselesi}

\section{The Question of Syncretism about Official and Literary Style in Old Turkic Civil Documents}

\author{
Kasimcan SADİKOV
}

Tashkent State Institute of Oriental Studies (Tashkent/Uzbekistan)

E-mail: kasimjonsadikov@gmail.com

A certain portion of the written documents found in the ruins of the ancient Turfan are official civil documents and they belong to the X.-XIII centuries. These civil documents consist of property owners, rich people, agriculturalists, and the trade. The article focus on three phrases in these documents: bar yoq bolmaq, örü qudı bolmaq and ičtin taštın bolmaq. They are reinterpreted from a different point of view.

Key Words: Old Turkic, civil documents, bar yoq bolmaq, örü qudı bolmaq and ičtin taštın bolmaq. 


\section{J(৫)}

Eski Turfan harabelerinde bulunan yazılı anitların belli bir kısmı resmî belgelerdir ve X.-XIII yüzyıllara aittir. Elyazmaları şu an Berlin'deki Brandenburg İlimler Akademisi kütüphanesinde, St. Petersburg'daki Rusya İlimler Akademisinin Şarkşinaslık Enstitüsü elyazmaları kütüphanesinde, Urumçi'deki Tarih Müzesinde saklanmaktadır.

Bu resmî yazılar yer, mülk sahipleri, zenginler, ziraatçılar, tebaanın alış veriş belgelerinden oluşmaktadır. Belgeler Uygur yazısı ile Eski Türkçede yazılmıştır. Bu ise devlet işlerinde, özellikle, resmî makamlarda Türkçenin, yazı işlerinde ise Uygur yazısının öneminin büyük olduğunu kanıtlar.

Genelde resmî üslup ya da diğer adıyla belgeler üslubu dediğimizde bu üslubun kesin ve net olması, çeşitli deyimlerin, pekiştirmelerin, edebî vasıtaların, edebî sanatların bulunmaması aklımıza gelir. Ama bu kural ilk ve orta asırlar, özellikle, eski Türk sivil belgelerinin üslubu için geçerli değildir. Çünkü söz konusu belgelerde konuşma diline, edebî üsluba ait vasitalar da bulunur. Kâtipler, resmî şahıslar fikrin daha net anlatılması, daha etkili olması, metnin daha güzel olması için edebî vasıtalara da müracaat etmişlerdir. Kısacası, belgelerin diline konuşma diliyle birlikte edebî üslubun ve Türk edebiyatının etkisi olmuştur. Bu durumu Eski Türkçede, özellikle, Türk yazı dili tarihindeki üsluplar senkretizmi olarak değerlendirmek lazımdır (Sodiqov 2015: 59-62).

Sivil belgeler arasında Köni Kuz isimli şahsın Burhan Kulı isimli kölesini azat ettiğini anlatan bir belge vardır (Sodiqov-Omonov 2012: 185-187). Belgenin metni şöyledir:

1. Taqıgu yıl üçünç ay iki yayıqa men

2. Köni Quz agır igkä tegip ölüp yitip

3. bargay men tep Şıyuy tuduy begkä

4. küdägüm Likäkä keyäşip aytışıp

5. Gäysidä tugmış Burxan Qulı atlıg

6. ogulanqa ögkä-qayqa buyanı

7. tegsün tep boş bitig berdim 


\section{$\mathrm{J}(\Theta)$}

8. bu küntä mınça Burxan Qulınıy ya

9. örü tagqa qudı quumqa barsar

10. öz köyülinçä buyan berip yorısun

\section{Metnin Aktarımı}

1. Tavuk yıll, üçüncü ayın ikinci gününde ben

2. Köni Kuz ağır hastalığa yakalanıp ölmeyeyim

3. diye Şınguy tudung beg,

4. damadım Lika ile anlaşıp,

5. Gangsi'de doğan Burhan Kulı isimli

6. oğlana (köle), anneme ve babama sevabı

7. değsin diye, özgürlük belgesi verdim.

8. Bugünden itibaren Burhan Kulı'nın (özgürlüğü kendi elinde),

9. yukarı dağa (mı gidecek), aşağı kuma (mı gidecek),

10. kendi gönlünce yapsın, sevap için yaşasın.

\section{Açlklamalar}

2.-3. satırlarda yer alan agir igkä tegip ölüp yitip bargay men tep cümlesi "ağır hastalığa yakalanıp ölürsem işim yarı yolda kalmasın" anlamındadır.

6.-7. satırlardaki buyanı tegsün tep "sevabı değsin, tevcih edilsin diye" anlamındadır. Ayrıca krş. buyan (< Sanskritçe punya) 'sevap, iyi; sevaplı amel, iş’.

9. satırda: örü tagqa qudı quumqa barsar örneğindeki örü tag 'yukarı dağ’ ve qudı quum ‘aşağı kum' karşılaştırması zıt anlamlı bir edebî sanatı göstermektedir.

Eski belgelerde resmî ve edebî üsluba karışık olarak rastlanması veya şahıslar nutkunun böyle senkretizm tarzında olması Türkçe resmî üslubun henüz oluşmadığını değil, aksine, onun çok ileri gittiğini, fikir aktarımını, belgelere resmiyet kazandırma imkânlarının çok geniş olduğunu, kâtibin bunlardan ustaca yararlanabildiğini göstermektedir. 


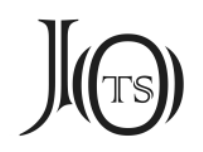

Şimdi belgelerde sık sık karşılanan berginçä yoq bar bolsar men sterotip tamlaması ve onun yorumu üzerinde duralım. Sözü geçen deyim 'borcu verene kadar varım yokum, veremezsem (borcu ödeyemezsem)' anlamındadır. Yasaya göre her verim garantili olmalı. İşte aynı bu durumu evraklarda resmî olarak kaydetmek için söz konusu cümle kullanılmaktadır.

Türkolojide yoq bar bol- veya bar yoq bol- ifadesi ‘ölüm' ile ilgili olduğunu birçok bilim adamı söylemiştir. Fakat bu konuda farklı yorumlar da bulunmaktadır. Örneğin, M. MORI'nin vurguladığı gibi, yoq bar bol- deyimi ‘ölüm'ü değil, borcu ödeme sırasında ödeyicinin 'orada bulunmamasını', yani onun ölmesi değil, belki borcu ödemeden firar etmesi ya da oradan başka yere taşınmasını ifade etmektedir. Söz konusu ifadenin diğer belgelerde içtin taştın bol-, örü qudı bol-gibi paradigmatik sıralarda gelmesine dayanarak, MORİ böyle bir sonuca varmıştır (Tuguşeva 1975: 32). Son zamanlarda MORİnin bu sonucu fende yaygınlaşmaya başladı. Bu ifadelerde herhangi bir durumda borcun mutlaka ödenmesi konusunda anlaşma imzalanmıştır. Fakat bu ifadenin her üç versiyonunu bir anlama bağlamak o kadar doğru değildir. Kanımızca onların hepsi ayrı ayrı anlamlara sahiptir. Aşağıda bu ifadenin her üçünün şekli ve onların anlamlarını inceleyeceğiz.

\section{Bar Yoq Bol- Üzerine}

Günümüzde biz Özbekler Beş künligim barmı yoq mı? "Beş günlüğüm var mı yok mu?" dediğimizde, burada, tabii ki, ölümü kast ederiz. Ya da söz konusu uzun bir süreyse, U zamāngäçä kim bar, kim yoq? "O zamana kadar kim var kim yok ?" denir. Bunun U zamāngäçä nimä gap, nimä söz? "O zamana kadar ne laf ne söz?" versiyonu da var. Bu cümlelerin tümünde adamın ölümü kastedilmektedir. Bunlara dayanarak, belgelerde geçen bar yoq bol- ifadesini da insanın ölümüne bağlamak daha mantıklı olur. Bu sırada bar bol- 'olmak, yaşamak' ifadesi Özbekçede 'var olun, yaşayın' anlamına gelir. yoq bol- 'yok olmak, ölmek', bar yoq bolsar ben denince ise 'eğer ölsem' anlamını taşır.

Örneğin, Qayımtudan tarı 'ufak tohumlu bitki' alınması hakkındaki belgede şu ifade dikkat çekicidir: berginçä bar yoq bolsar men inim Barçaqı anı tegilär bilä köni 


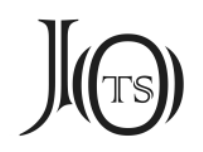

bersünlär "Verince var yok olsam (varım yokum) kardeşim Barçakı onu kardeşleri ile ödesinler" (Sodiqov-Omonov 2012: 158-159).

\section{Örü Qudı Bol- Üzerine}

Rusya İlimler Akademisinin Şarkşinaslık Enstitüsü elyazmaları kütüphanesinde SI 1449 (SI Kr IV/329) kayıt numarası altında bulunmakta olan borçla alınmış bir kumaş ile ilgili belgede şöyle bir cümleye rastlarız: Berginçä örü qudı bolsar men inim Bilär köni bersün. Bu cümledeki berginçä örü qudı bolsar men kısmını TUGUŞEVA "Eğer borcu ödenmesine kadar yukarı ya da aşağıda, kuzeyde ya da güneyde olsam" diye çevirmiştir (2013: 41). Tercümede 'kuzeyde ya da güneyde' derken ZIEME'nin fikirlerine dayanılmıştır. Çünkü ZIEME örü qudı ile kutupları (güney ve kuzey) kastetmiştir, yani metindeki örü qudı bolsar men cümlesini "ister kuzeyde olayım, ister güneyde" diye tercüme etmiştir. ZIEME, örü tagqa, qudl quumqa bar- cümlesinin anlamını delil olarak göstererek, şöyle bir sonuca varmıştır: örü tagqa'yı 'güneye' diye anlamış ve ona bağlı halde örü'yü 'güney', onun zıt anlamı qudi’yı da 'kuzey' olarak düşünmüştür.

Tarihsel kaynaklarda tag sözcüğü 'kuzey' anlamında da kullanılmıştır: öydün yıgaq 'doğu', kündün yııaq 'güney', kedin yınaq 'batı', tagdın yınaq 'kuzey’i bildirmektedir. Örneğin, Sada adındaki birisinin Solda ağadan bez aldığı ve onun karşıtı olarak da üzüm bahçesini sattığı hakkındaki belgede bunlar şöyle geçmektedir: Bu borluqnıy sıçısı: öydüni Qara Temürniy borluq adırar; kündüni yınaq sıçısı ögän adırar; kedin yııaq sıcısı ögän-ök adırar; tağdın sıçısı Surıqa tegmiş borluq adırar "Bu üzüm bahçesinin sınırı: doğudan Kara Timur’un üzüm bahçesi ile sınırları vardır, güney taraftaki sınırı nehre kadar uzanır, batı taraftaki sınırı da nehre kadar uzanır, dağ taraftaki yani kuzeydeki sınırı da Suri'ye ait olan bahçeyi ayırır" (Sodiqov-Omonov 2012: 170-173).

Kuzeye karşı dağ kelimesinin kullanılması herhalde Turfan bölgesi ahalisinin düşünceleriyle ilgili olabilir. Çünkü Turfan vahasının kuzey tarafı dağlarla sarılıdır. Söz konusu belgelerde geçen örü tagqa qudı quumqa barsar cümlesine gelince, bu cümlede 'güney' ve 'kuzey' anlamı yoktur. Cümledeki örü tag 'yukarı dağ', qudı quum 'aşağı kum, dört taraf', yani 'herhangi bir yer' anlamındadır. Cümle, "İster yukarı dağa gitsin, ister aşağı kuma gitsin, yani istediği yerde, her 


\section{$J(\Theta)$}

yerde" anlamındadır. Onun örneği de budur: Bu küntä mınça Burxan Qulını ya örü tagqa qudı quumqa barsar öz köyülinçä buyan berip yorısun "Bugünden itibaren Burhan Kulı'nın (özgürlüğü kendi elinde), yukarı dağa (mı gidecek), aşağı kuma (mı gidecek), kendi gönlünce yapsın, sevap için yaşasın" (Sodiqov-Omonov 2012: 185-187).

Bununla birlikte, örü qudı bol- ifadesinde de 'güney' ve 'kuzey' anlamı yoktur. Belgelerde geçen örü qudı bol- ifadesi, bize göre iki anlam taşır. İlkin, 'yoksullaşmayı' anlatır: örü’nün asıl anlamı 'yukarı' demektir, mecaz anlamda zenginliğe karşı kullanılır. qudinın asıl anlamı 'aşağı' demek olup mecaz (yan) anlamda yoksulluğa karşı kullanılır. Belgelerde Berginçä örü qudı bolsar men şeklinde bulunmaktadır. Bu cümle "(Borcu) ödeyene dek yoksulluğa düşsem bile, onu ödemeye kefilim" anlamını taşımaktadır.

Yukarıda adı geçen belgede biraz değişik anlam kazandığını görebilmekteyiz. Orada örü qudı bol- ibaresi ticaret karşıllğında kullanılarak zenginlik ve yoksulluğu anlatır: örü bol- 'yukarı olmak, yükselmek', yani 'iyi yetinmek, zenginleşmek'; qudı bol- 'aşağıya inmek', yani 'yoksullaşmak' demektir; örü qudı bol- 'yukarı aşağı olmak', yani 'yoksulluğa düşmek, hiçbir şeysiz kalmak' anlamındadır.

Zit anlamlı kelimelerin tekrarlanması yoluyla yeni kelimeleri oluşturmak günümüz Özbekçesinde de bulunmaktadır: dost duşman bar "dost düşman var" dediğimizde "düşmanlara karşı dikkatli olmak", aq qaranı tanıdı "ak karayı tanıdı" dediğimizde "hayatta her türlü insanlarla karşılaştı; kötüden korunmasını öğrendi” anlaşılır vs. Bundan dolayı, örü qudı bolsar men cümlesini "yukarı aşağı olsam; hiçbir şeysiz kalsam; yoksulluğa düşsem" diye yorumlarsak daha mantıklı olur.

Belgede geçen örü qudı bol- ifadesinin başka bir anlamı daha var, bu da “ölüm” ile ilgilidir. örü bol- 'kalkmak', yani 'yaşamak'; qudı bol- 'aşağı olmak, inmek', yani 'ölmek'; örü qudı bolsar men "(eğer) ölsem, varım yokum” demektir. Metin de ona göre yorumlanır. Bunun örneği de şöyledir: Berginçä örü qudı bolsar men inim Bilär köni bersün "Ödeyene dek yukarı aşağı olsam [yani varım var, yokum var / zengin ya da yoksul olursam / bir şey olursa], kardeşim Biler mutlaka ödesin" (Tuguşeva 2013: 41). 


\section{J(৫)}

\section{İçtin Taştın Bol- Üzerine}

İfadenin bu versiyonunda da "ölüm” anlamı yoktur. içtin 'içeride', yani 'kendi evimde'; taştın 'dışarıda', yani 'daha uzak bir yerde'; içtin taştın bol- 'uzak bir yerde olmak' anlamında kullanılır. Metinlerde Berginçä içtin taştın bolsar men olarak kullanılmıştır, bu da "(Borcu) ödeyene dek uzak bir ülkelere gideceksem" anlamına gelir. Borç alan bir neden yüzünden taşınacak olsa veya kaçsa da, fark etmez, borcu ödemek sorumluluğunu aldığı zaman, işte bu ifadeyi kullanmıştır.

Örneğin, Bulmış adlı birisinin Kösünçü’nden borç aldığı gümüş hakkındaki belgede: Berginçä içtin taşın bolsar men inim Ayqt<a>çı (?) köni bersün "Ödeyene dek içeride veya dışarıda [kendi evimde veya dışta - uzak bir yerlerde] olsam, kardeşim Aytqaçı mutlaka ödesin” (Tuguşeva 2013: 48). Baburname'de bu işkäri taşqarı tüş- kelime öbeği halinde 'esir, tutkun' anlamında bulunmaktadır: Āxir Badiu-zzamān mirzā araga tüşüp, yaraşup, içkäri taşqarı tüşkän yigitlärni alışıp yandılar (1989: $35)$.

\section{Sonuç}

İște, bar yoq bol-, örü qudı bol- ve içtin taştın bol- aynı kalıptaki ifadeler olmasına rağmen, bunlar üç farklı anlamda kullanılmıştır. Bunlardan bar yoq bol'ölüm'ü ima eder; diğeri 'zenginlik ve yoksulluk', bununla birlikte 'ölüm'e de ima eder. örü qudı bol- 'hiçbir şeysiz kalmak; yoksulluğa düşmek' ve 'vefat etmek' demektir. İçtin taştın bol- 'burada oturmamak, uzak ülkelere taşınmak' anlamındadır. Söz konusu ifadeleri yorumlamada, onların esasını Budizm etkisi altında başka halklardan geçmiştir diye bakılmamalıdır. Onlar Eski Türkçenin iç koşulları, Türk halklarının millî geleneği, bakış açısı etkisiyle gelişmiştir. İlk orta yüzyıllardan kalma belgelerin yeni neşirlerinde bunun gibi yorumlar da hesaba katılmalıdır.

\section{Kaynakça}

SoDiQov, Q. (2015). Eski Turkey Hujjatlar: Matn İnterpretatsiyasi va Stilistikasi, Toşkent.

SoDiQov, Q. \& Q. OMONov (2012) Q. Turkiy Hujjatchilikning Tarixiy İldizlari, Toşkent. 


\section{J(৫)}

Zahiriddin Muhammad Bobur (1989). Boburnoma, Toşkent.

TuguşeVA, L. Y. (1975). "Yazikoviye i Vneyazikovie Znaçeniya v Deşifrovke Pamyatnikov Drevneuygurskoy Pismennosti”, Sovyetskaya Turkologiya, 5: 27-32.

TuguşeVA, L. Y. (2013). Uygurskiye Deloviye Dokumenti X-XIV vv. iz Vostoçnogo Turkestana, Moskva: Nauka \& Vostochnaya Literatura Publishers. 